\title{
Differentiation of Bordetella avium and Related Species by Cellular Fatty Acid Analysis
}

\author{
CHRIS J. MOORE, HUGH MAWHINNEY, AND PATRICK J. BLACKALL* \\ Animal Research Institute, Yeerongpilly 4105, Australia
}

Received 22 September 1986/Accepted 10 March 1987

\begin{abstract}
The fatty acids of 18 strains of Bordetella avium, 3 strains of Alcaligenes faecalis, 5 strains of Bordetella bronchiseptica, and 12 strains of a $B$. avium-like organism were examined by gas chromatography-mass spectrometry. The presence of a significant amount of the acid 2-OH $C_{14: 0}$ characterized $B$. avium and the $B$. avium-like organism. $B$. avium and the $B$. avium-like organism differed in their relative concentrations of $C_{16: 1}$ and 3-OH $C_{14: 0}$ acids. $B$. bronchiseptica and $A$. faecalis were distinguishable by comparison of the relative concentrations of $C_{18: 0}$ and $C_{18: 1}$ acids.
\end{abstract}

In the late 1970 s a gram-negative, motile, asaccharolytic bacterium was associated with an acute respiratory disease of turkey poults (5). The disease has since been reported by other workers, although different terms were used, e.g., rhinotracheitis (14) and bordetellosis (6).

Considerable confusion and disagreement have occurred concerning the classification of the disease agent. It has been termed Bordetella-like (6), Alcaligenes faecalis (15), and Bordetella meleagridis or Alcaligenes meleagridis (13). Kersters et al. (11) demonstrated that the agent is a member of the genus Bordetella and proposed the new species Bordetella avium. In addition, recent studies have indicated that an organism very similar to $B$. avium also occurs in chickens and turkeys $(1,7,13 ;$ P. J. Blackall and C. M. Doheny, Aust. Vet. J., in press). We have adopted the suggestion of Jackwood et al. (8) and use the term $B$. avium-like for this organism.

A major reason for the confusion over the identification and classification of $B$. avium is that this organism is relatively inert and hence the conventional tests yield mainly negative results. These negative results make separation of $B$. avium from other similar inert organisms such as $A$. faecalis or Bordetella bronchiseptica difficult.

In recent years, gas chromatographic profiling of the cellular fatty acid composition of bacterial cells has been successfully used to classify and identify many bacteria (9). In particular, the technique has been used to identify members of the genera Alcaligenes (4) and Bordetella $(3,10)$. Recently, Jackwood et al. (8) described, for the first time, the fatty acid profiles of $B$. avium and the $B$. avium-like organism.

This report presents the results of our gas chromatography-mass spectrometry studies of the cellular fatty acid composition of $B$. avium, the $B$. avium-like organism, $A$. faecalis, and $B$. bronchiseptica. They provide some criteria for the separation of these four organisms based on their fatty acid profiles. These criteria are particularly useful for laboratories with access to high-resolution (capillary) gas chromatographs but lacking the software necessary for rapid probability-based identification. In addition, we clarify some ambiguities in the literature concerning the fatty acid profiles of members of the genus Bordetella.

\footnotetext{
* Corresponding author.
}

\section{MATERIALS AND METHODS}

Cultures. The field isolates of $B$. avium (12 strains) and the $B$. avium-like organism (10 strains) have been described elsewhere (2; Blackall and Doheny, in press). The reference strains used are given in Table 1.

Cell preparation and derivative formation. Bacteria were grown on brain heart infusion agar (GIBCO Laboratories, Brisbane, Australia) with $5 \%$ sheep blood for $16 \mathrm{~h}$ at $37^{\circ} \mathrm{C}$ in an atmosphere of $5 \% \mathrm{CO}_{2}$. The confluent growth from three plates was gently harvested in sterile distilled water and washed once, and the cells were resuspended in $3 \mathrm{ml}$ of sterile distilled water divided into $1-\mathrm{ml}$ aliquots, and stored at $-20^{\circ} \mathrm{C}$. The fatty acid methyl esters were then prepared (12).

Gas chromatography-mass spectrometry. Gas chromatographic-mass spectrometric analysis was performed on a Finnigan 1020B spectrometer equipped with a data system and a National Bureau of Standards library. Chromatography was performed on a DB-5 fused silica column $(30 \mathrm{~m}$ by $0.25 \mathrm{~mm}$ ) (J \& W Scientific Inc., Rancho Cordova, Calif.) interfaced directly to the mass spectrometer ion source. Injector and interface ovens were maintained at $250^{\circ} \mathrm{C}$. Injection was splitless (30 s), with an oven temperature of $120^{\circ} \mathrm{C}$. After $2 \mathrm{~min}$, the oven temperature was raised by a linear gradient of $7^{\circ} \mathrm{C} / \mathrm{min}$ to $260^{\circ} \mathrm{C}$, where it was maintained for $8 \mathrm{~min}$. The total analysis time was $30 \mathrm{~min}$. The carrier gas was helium, with a linear flow rate of $30 \mathrm{~cm} / \mathrm{s}$ at $120^{\circ} \mathrm{C}$. The mass spectrometer was operated in the electron impact mode and scanned from 35 to 350 atomic mass units in $1 \mathrm{~s}$. Identification of peaks was performed by using the library search facility, by comparison with published spectra, or by analysis of authentic material. Quantification was performed by the software by using a retention time window of $800 \mathrm{~s}$, sufficient to include all fatty acid methyl esters from $C_{10: 0}$ to $\mathrm{C}_{\text {19:0. }}$. This resulted in over 50 components commonly being included in the quantification with the major components (Table 2), constituting ca. $85 \%$ of the total integrated area.

\section{RESULTS}

The range of relative concentrations of cellular fatty acids detected in the B. avium, B. avium-like organism, $A$. faecalis and $B$. bronchiseptica strains are presented in Table 2 . We found little difference for the isolates within each of the four groups. The chromatograms of the type strains of the three 
TABLE 1. Identification, origins, and sources of reference strains

\begin{tabular}{|c|c|c|}
\hline Organism & Origin & Source ${ }^{a}$ \\
\hline \multicolumn{3}{|l|}{ B. avium } \\
\hline $270-80$ & $\begin{array}{l}\text { Goose, Federal Republic } \\
\text { of Germany }\end{array}$ & Hinz \\
\hline $383-78$ & $\begin{array}{l}\text { Turkey, Federal Republic } \\
\text { of Germany }\end{array}$ & Hinz \\
\hline $591-77$ & $\begin{array}{l}\text { Turkey, Federal Republic } \\
\text { of Germany }\end{array}$ & Hinz \\
\hline P-8 & Turkey, United States & Simmons \\
\hline 002 & Turkey, United States & Jackwood \\
\hline 197 & Turkey, United States & Jackwood \\
\hline \multicolumn{3}{|l|}{ B. avium-like } \\
\hline 128 & Turkey, United States & Jackwood \\
\hline 154 & Turkey, United States & Jackwood \\
\hline \multicolumn{3}{|c|}{ B. bronchiseptica } \\
\hline 186 & Turkey, United States & Jackwood \\
\hline 188 & Turkey, United States & Jackwood \\
\hline ATCC 19395 & Dog & ATCC \\
\hline ATCC 4617 & $\mathrm{NK}^{b}$ & ATCC \\
\hline NCTC 8344 & NK & NCTC \\
\hline \multicolumn{3}{|l|}{ A. faecalis } \\
\hline ÄTCC 8750 & NK & ATCC \\
\hline NCIB 9650 & NK & UQM \\
\hline ATCC 19018 & NK & Glenfield \\
\hline
\end{tabular}

${ }^{a}$ Hinz, K.-H. Hinz, Klinik fur Gleflugel der Tierarztlichen, Hannover, Federal Republic of Germany; Simmons, D. G. Simmons, School of Veterinary Medicine, North Carolina State University, Raleigh, N.C.; Jackwood, M. W. Jackwood, Ohio Agricultural Research and Development Center, Wooster, Ohio; NCTC, National Collection of Type Cultures, Central Public Health Laboratory, London, United Kingdom; UQM, University of Queensland Culture Collection, Brisbane, Australia; Glenfield, Central Veterinary Laboratory, Glenfield, Australia.

${ }^{b}$ NK, Not known.

recognized species are shown in Fig. 1. The peak marked $X$ is an artifact most probably derived from the $C_{17}$ cyclopropane (cyc) acid during esterification.

The cellular fatty acids of the three species and the $B$. avium-like organisms were qualitatively similar. The major fatty acids present were $C_{12: 0}, C_{14: 0}, C_{15: 0}, C_{16: 0}, C_{16: 1}, C_{17: 0}$, $\mathrm{C}_{17}$ cyc, $\mathrm{C}_{18: 0}, \mathrm{C}_{18: 1}$, and the hydroxy acids $2-\mathrm{OH} \mathrm{C}_{12: 0}$ and 3-OH $\mathrm{C}_{14: 0}$. The acids $\mathrm{C}_{16: 0}$ and $\mathrm{C}_{17}$ cyc constituted about $60 \%$ of the total cellular fatty acids for all of the isolates examined.

Examination of the cellular fatty acid profiles allowed the four groups of organisms to be clearly spearated. All the $B$. avium and $B$. avium-like isolates had a $2-\mathrm{OH} \mathrm{C}_{14: 0}$ content which, although small, was much larger than that of any $A$. faecalis or $B$. bronchiseptica isolate. The $B$. avium-like isolates could be separated from $B$. avium by a comparison of the ratios of $\mathrm{C}_{16: 1}$ and $3-\mathrm{OH} \mathrm{C}_{14: 0}$ acids. All $B$. avium isolates had a $C_{16: 1}$ content lower than that of the closely adjacent 3-OH $\mathrm{C}_{14: 0}$, whereas all the $B$. avium-like isolates had a $\mathrm{C}_{16: 1}$ content higher than the $3-\mathrm{OH} \mathrm{C}_{14: 0}$ content.
$B$. bronchiseptica and $A$. faecalis were most easily separated by comparison of the ratios of $C_{18: 0}$ and $C_{18: 1}$ acids. The three $A$. faecalis isolates showed a $C_{18: 1}$ content greater than the $\mathrm{C}_{18: 0}$ content. For the five $B$. bronchoseptica isolates, the reverse was true, i.e., the $C_{18: 0}$ content was higher than the $\mathrm{C}_{18: 1}$ content. All the isolates of $B$. avium and the $B$. avium-like organisms also had a $\mathrm{C}_{18: 0}$ content greater than the $\mathrm{C}_{18: 1}$ content.

The means of the concentrations of the fatty acids useful in separating the four taxa (3-OH $\mathrm{C}_{14: 0}, \mathrm{C}_{16: 1}, \mathrm{C}_{18: 1}$, and $\left.\mathrm{C}_{18: 0}\right)$ are presented in Table 3.

\section{DISCUSSION}

The cellular fatty acid contents, as determined by gas chromatography-mass spectrometry, allowed the ready recognition of the four taxa examined in this study, B. avium, the $B$. avium-like organism, $A$. faecalis, and $B$. bronchiseptica. Although the four taxa all had $C_{16: 0}$ and $C_{17}$ cyc as the major fatty acids, the ratios of the minor components clearly separated the organisms (Table 2 and Fig. 1).

Our findings are, in general, in agreement with those of a similar study performed by Jackwood et al. (8). In both studies, $B$. avium and the $B$. avium-like organism were readily distinguished from $A$. faecalis and $B$. bronchiseptica by the presence of significant amounts of $2-\mathrm{OH} \mathrm{C} \mathrm{C}_{14: 0}$. However, Jackwood et al. (8) based their differentiation of $B$. avium and the $B$. avium-like organism on statistically significant differences between their $C_{16: 0} / C_{14: 0}, C_{16: 0} / C_{18: 0}$, and 2-OH $\mathrm{C}_{14: 0} / 2-\mathrm{OH} \mathrm{C}_{12: 0}$ ratios and by use of the HewlettPackard 5898A microbial identification system. In contrast, our results suggest a much more convenient distinguishing feature: $B$. avium isolates had a $\mathrm{C}_{16: 1}$ content lower than that of 3-OH $\mathrm{C}_{14: 0}$, whereas $B$. avium-like isolates had a $\mathrm{C}_{16: 1}$ content higher than that of 3-OH $\mathrm{C}_{14: 0}$.

Our examination of $18 \mathrm{~B}$. avium isolates and $12 \mathrm{~B}$. aviumlike isolates from three continents showed the $\mathrm{C}_{16: 1} / 3-\mathrm{OH}$ $C_{14: 0}$ ratio to be a simple and completely reliable method of separating $B$. avium and the $B$. avium-like organism. We emphasize that this subtle but significant difference between $B$. avium and the $B$. avium-like organism necessitates strict adherence to our conditions of growth and chemical workup. Further work on the effects of various incubation conditions and different media is planned.

In agreement with Jackwood et al. (8), we found that the avian isolates of $B$. bronchiseptica possessed fatty acid profiles very similar to those of the reference strains obtained from other animals.

There has been some disagreement concerning the $C_{18: 0}$ and $\mathrm{C}_{18: 1}$ content of members of the genus Bordetella. In the study by Jantzen et al. (10) of 13 Bordetella pertussis isolates, 3 Bordetella parapertussis isolates, and $7 \mathrm{~B}$. bronchiseptica isolates, the chromatograms illustrated show a $\mathrm{C}_{18: 0}$ content greater than the $\mathrm{C}_{18: 1}$ content. However, in

TABLE 2. Cellular fatty acid composition of strains of B. avium, the B. avium-like organism, B. bronchiseptica, and A. faecalis

\begin{tabular}{|c|c|c|c|c|c|c|c|c|c|c|c|c|}
\hline \multirow{2}{*}{$\begin{array}{c}\text { Organism } \\
\text { (no. of strains) }\end{array}$} & \multicolumn{12}{|c|}{$\%$ of total fatty acids } \\
\hline & $C_{12: 0}$ & $\begin{array}{c}2-\mathrm{OH} \\
\mathrm{C}_{12: 0}\end{array}$ & $C_{14: 0}$ & $\begin{array}{l}2-\mathrm{OH} \\
\mathrm{C}_{14: 0}\end{array}$ & $\begin{array}{l}3-\mathrm{OH} \\
\mathrm{C}_{14: 0}\end{array}$ & $C_{15: 0}$ & $C_{16: 0}$ & $C_{16: 1}$ & $C_{17: 0}$ & $\mathrm{C}_{17} \mathrm{cyc}$ & $\mathrm{C}_{18: 0}$ & $\mathrm{C}_{18: 1}$ \\
\hline & & $1.4-2.1$ & & $1.5-2.6$ & $3.0-4.6$ & & & & & $19.0-30.0$ & $7.0-13.0$ & \\
\hline & & & & & & $0.4-1.4$ & 35.0 & $6.0-17.0$ & $0.9-2.0$ & 14. & & $1.2-2.3$ \\
\hline A. faecalis & $1.0-2.0$ & $1.0-2.5$ & $0.5-1.5$ & $<0.2$ & $4.3-8.2$ & $0.2-1.2$ & $34.0-40.0$ & $6.5-14.0$ & $0.8-1.0$ & $15.0-23.0$ & & \\
\hline B. avium-like (12) & $0.4-1.1$ & $1.0-3.3$ & $0.6-1.3$ & $1.5-4.0$ & $3.4-5.1$ & $0.2-0.4$ & $31.0-38.0$ & $5.5-12.0$ & $0.9-2.4$ & $11.0-23.0$ & $5.0-9.0$ & $1.0-2.7$ \\
\hline
\end{tabular}



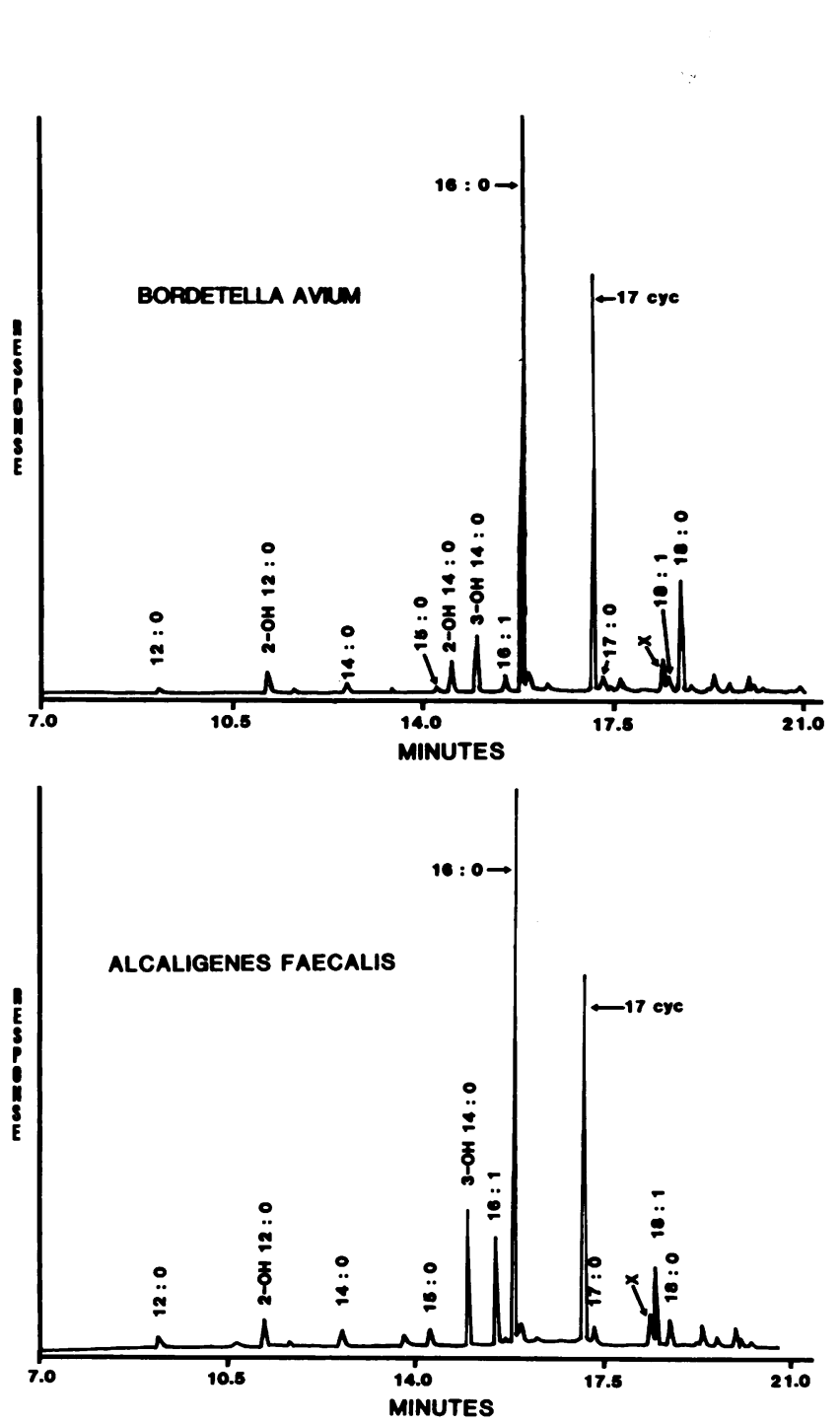

table accompanying the chromatograms, the values for $B$. bronchiseptica and $B$. parapertussis indicate a reverse ratio, i.e., $C_{18: 1}$ content greater than $C_{18: 0}$ content. Dees et al. (3) reported similar levels of $C_{18: 0}$ and $C_{18: 1}$ in five isolates of $B$. bronchiseptica. Jackwood et al. (8) reported that $13 B$. bronchiseptica isolates and $5 B$. parapertussis isolates were all characterized by a $C_{18: 1}$ content greater than the $C_{18: 0}$ content. However, for $59 \mathrm{~B}$. avium isolates and $46 \mathrm{~B}$. avium-like isolates, Jackwood et al. (8) reported the opposite ratio, i.e., $C_{18: 0}$ content greater than $C_{18: 1}$ content. In contrast, we found that all Bordetella isolates we examined (18 $B$. avium isolates, $5 \mathrm{~B}$. bronchiseptica isolates, and $12 \mathrm{~B}$. avium-like isolates) had a $C_{18: 0}$ content greater than the $C_{18: 1}$ content.

It is possible that peak $\mathrm{X}$ in Fig. 1, clearly identifiable as an artifact by mass spectrometry and most probably derived from $\mathrm{C}_{17}$ cyc during esterification, may have contributed to this confusion concerning the $\mathrm{C}_{18: 0} / \mathrm{C}_{18: 1}$ ratio. The identities and origins of this and similar artifacts have been described by Vulliet et al. (16). The major fragments in its mass spectrum are at $m / e 129$ and $m / e$ 201. Laboratories basing fatty acid identification on retention time data could misidentify this artifact as a $\mathrm{C}_{18: 1}$ isomer. Our results show that a $\mathrm{C}_{18: 1}$ isomer was occasionally detectable superimposed on the artifact. In such instances, it was present only in trace quantities $(<0.2 \%)$.

It is likely that for bacterial species in which the $\mathrm{C}_{17}$ cyc component is at a low level or absent, no ambiguity due to the artifact would arise. This may explain why Jantzen et al. (10) reported that the $C_{18: 0}$ content of $B$. pertussis, an organism containing only trace levels of $C_{17}$ cyc, was greater than the $\mathrm{C}_{18: 1}$ content.

In species in which the $\mathrm{C}_{18: 0}$ component is sufficiently large, the mistaken inclusion of the artifact as a $C_{18: 1}$ isomer would not result in a $C_{18: 1}$ content greater than the $C_{18: 0}$ content. This may explain why Jackwood et al. (8) reported that all their B. avium and $B$. avium-like isolates had a $C_{18: 0}$ content greater than the $C_{18: 1}$ content yet reported the opposite for their B. bronchiseptica and B. parapertussis isolates.

In contrast to our results for the three Bordetella taxa, we found that the three $A$. faecalis isolates had the reverse ratio of $\mathrm{C}_{18: 0}$ and $\mathrm{C}_{18: 1}$ acids, i.e., a $\mathrm{C}_{18: 1}$ content greater than the $\mathrm{C}_{18: 0}$ content. Previous studies of 29 A. faecalis isolates, 4 Alcaligenes denitrificans isolates, and 11 "Alcaligenes odorans" isolates have all reported a similar finding $(3,4,8)$.

Our results suggest that when isolates of $A$. faecalis, $B$. bronchiseptica, $B$. avium, and the $B$. avium-like organism are examined for cellular fatty acids by using the growth medium and conditions we describe, the ratios of $\mathrm{C}_{18: 0}$ and $\mathrm{C}_{18: 1}$ fatty acid contents provide a clear distinction between the two genera.

As also reported by Jackwood et al. (8), we found that all of our isolates of B. avium and the B. avium-like organism possessed significant amounts of $2-\mathrm{OH} \mathrm{C}_{14: 0}$. In contrast, our 
$A$. faecalis and $B$. bronchiseptica isolates possessed only trace amounts of this acid. Other studies have confirmed the absence of this acid in other members of the genus Bordetella $(3,8,10)$.

Small amounts of 2-OH $\mathrm{C}_{14: 0}$ have been found in some isolates of $A$. faecalis $(4,8)$. This finding would still not confuse the identification of $B$. avium or the $B$. avium-like organism. The ratio of the $\mathrm{C}_{18: 0}$ and $\mathrm{C}_{18: 1}$ content would still clearly separate any 2-OH $\mathrm{C}_{14: 0}$-containing $A$. faecalis isolates from $B$. avium or the $B$. avium-like organism.

In summary, we confirmed that the four taxa, B. avium, the $B$. avium-like organism, $B$. bronchiseptica, and $A$. faecalis possess distinct cellular fatty acid profiles. The three members of the genus Bordetella could be distinguished from $A$. faecalis by comparison of the relative amounts of $\mathrm{C}_{18: 0}$ and $\mathrm{C}_{18: 1}$ acids present. $B$. avium and the $B$. avium-like organism contained the acid 2-OH $\mathrm{C}_{14: 0}$ at much higher levels than did B. bronchiseptica or A. faecalis. B. avium and the $B$. avium-like organism could be separated by a comparison of the relative amounts of $\mathrm{C}_{16: 1}$ and 3-OH $\mathrm{C}_{14: 0}$ acids. For diagnostic veterinary laboratories with access to a high-resolution gas chromatograph, the detection of cellular fatty acid profiles offers a rapid and reliable method for the identification of $B$. avium and the $B$. avium-like organism.

\section{ACKNOWLEDGMENTS}

This work was supported in part by a grant from the Australian Chicken Meat Research Committee.

The technical assistance of C. Doheny and D. Rogers is gratefully acknowledged. We ackowledge the assistance of E. Jantzen, who drew our attention to the report of Vulliet et al. (16) on the occurrence of cyclopropane fatty acid-derived artifacts.

\section{LITERATURE CITED}

1. Berkhoff, H. A., and G. D. Riddle. 1984. Differentiation of Alcaligenes-like bacteria of avian origin and comparison with Alcaligenes spp. reference strains. J. Clin. Microbiol. 19: 477-481.

2. Blackall, P. J., and J. G. Farrah. 1985. Isolation of Bordetella avium from poultry. Aust. Vet. J. 62:370-372.

3. Dees, S., S. Thanabalasundrum, C. W. Moss, D. G. Hollis, and R. E. Weaver. 1980. Cellular fatty acid composition of group
IVe, a nonsaccharolytic organism from clinical sources. J. Clin. Microbiol. 11:664-668.

4. Dees, S. B., and C. W. Moss. 1975. Cellular fatty acids of Alcaligenes and Pseudomonas species isolated from clinical specimens. J.Clin. Microbiol. 1:414-419.

5. Hinz, K.-H., G. Glunder, and H. Luders. 1978. Acute respiratory disease in turkey poults caused by a Bordetella bronchiseptica-like bacteria. Vet. Rec. 103:262-263.

6. Hinz, K.-H., G. Glunder, B. Stiburek, and H. Luders. 1979. Experimentalle untersuchungen zur Bordetellose der pute. Zentralbl. Veterinaermed. Reihe B 26:202-213.

7. Jackwood, M. W., Y. M. Saif, P. D. Moorehead, and R. N. Derth. 1985. Further characterization of the agent causing coryza in turkeys. Avian Dis. 29:690-705.

8. Jackwood, M. W., M. Sasser, and Y. M. Saif. 1986. Contribution to the taxonomy of the turkey coryza agent: cellular fatty acid analysis of the bacterium. Avian Dis. 30:172-178.

9. Jantzen, E. 1984. Analysis of cellular components in bacterial classification and diagnosis, p. 257-302. In G. Odham, L. Larsson, and P.-A. Mardh (ed.), Gas chromatography/mass spectrometry applications in microbiology. Plenum Publishing Corp., New York.

10. Jantzen, E., E. Knudsen, and R. Winsnes. 1982. Fatty acid analysis for differentiation of Bordetella and Brucella species. Acta Pathol. Microbiol. Immunol. Scand. Sect. B 90:353-359.

11. Kersters, K., K.-H. Hinz, A. Hertle, P. Segers, A. Lievens, O. Siegmann, and J. De Ley. 1984. Bordetella avium sp. nov., isolated from the respiratory tracts of turkeys and other birds. Int. J. Syst. Bacteriol. 34:56-70.

12. Lambert, M. A., F. W. Hickman-Brenner, J. J. Farmer III, and C. W. Moss. 1983. Differentiation of Vibrionaceae species by their cellular fatty acid composition. Int. J. Syst. Bacteriol. 33:777-792.

13. Rimler, R. B., and D. G. Simmons. 1983. Differentiation among bacteria isolated from turkeys with coryza (rhinotracheitis). Avian Dis. 27:491-500.

14. Simmons, D. G., and J. G. Gray. 1979. Transmission of acute respiratory disease (rhinotracheitis) of turkeys. Avian Dis. 23:132-138.

15. Simmons, D. G., L. P. Rose, and J. G. Gray. 1980. Some physical, biochemic and pathologic properties of Alcaligenes faecalis, the bacterium causing rhinotracheitis (coryza) in turkey poults. Avian Dis. 24:82-90.

16. Vulliet, P., S. P. Markey, and T. G. Tornabene. 1974. Identification of methoxyester artifacts produced by methanolic- $\mathrm{HCl}$ solvolysis of the cyclopropane fatty acids of the genus Yersinia. Biochim. Biophys. Acta 348:299-301. 